\title{
Physiotherapy in the Covid ward:Where compassion overcomes fear
}

\author{
MARIYA PRAKASH JIANDANI
}

\begin{abstract}
The narrative is an account of the personal experience of a cardiopulmonary physiotherapist inside the Covid ICU, when the city of Mumbai was brought to a standstill. It describes the need to seek an opportunity to face the challenges, guided by intuition and one's skill set to help those fighting to survive Covid. Facing a new and complex disease meant having to create guidelines for treatment, overcome the patients' despair, and even cope with the cumbersome protective gear.But the gradual improvement in patients' health and their joy on recovering inspired us to put in more effort with unity, dedication and will power, standing together to face the pandemic, enabling us to realise what is required of us, now and in the future - striving to better ourselves in the science of health each day.
\end{abstract}

Keywords: Covid-19, patient care, cardio-pulmonary physiotherapy, lung disease

"Corona", a word that scared every individual all over the globe, had sneaked into the city of Mumbai. The prestigious tertiary care hospital in the heart of Mumbai where I work started witnessing a massive inflow of patients testing positive for Covid-19. Doctors were fighting night and day to help people recover. I wondered as I watched, where I stood and how I could help. Something within urged me to enter those wards and do justice to the oath I had taken. Being a cardiopulmonary physiotherapist, I knew the importance of breathing well. I recalled the comfort that I had been able to provide in the past to my patients with interstitial lung disease who would struggle to breathe and needed oxygen.

Colleagues working in dedicated Covid hospitals inquired as to what could be done. "Is chest physiotherapy ok?" was the frequent query. It was an unknown world for me too, except for the experience I had gained over years of treating critically ill patients. "Tell me do they have secretions? Can they breathe, can they move in bed or walk? How are their enzyme levels? Is the ECG normal? What are the x-rays like?" were my questions in response. The curiosity was to identify and grapple with

Author: Mariya Prakash Jiandani (mpjiandani@gmail.com), Associate Professor, Physiotherapy School and Centre, Seth GS Medical College and KEM Hospital, Parel, Mumbai 400012 INDIA.

To cite: Jiandani M P. Physiotherapy in the Covid ward: Where compassion overcomes fear. Indian J Med Ethics. 2021 Jan-Mar; 6(1) NS: 23-24. DOI: 10.20529/IJME.2020.090

Published online first on August 27, 2020.

(c) Indian Journal of Medical Ethics 2020 those problems which could be treated by physiotherapy.

My intuition said this disease was far more complex and needed to be dealt with more delicately, systematically and differently. Patient safety was a prime concern along with safety of the therapist. The incidence of myocarditis, sudden deaths and thromboembolism were already a part of the literature. Numerous questions reeled through my mind. Will physiotherapy be beneficial? Are they stable enough to be treated? What is it that needs to be done differently? My critical questioning increased with every phone call, and I was left discussing all the probabilities for hours.

The first step was to get all the experts together, create a new set of guidelines to benefit all the therapists working in the Covid centres of India. A consensus building exercise, to keep updating and answering the questions that arose with the increasingly definitive role of physiotherapy, had begun. I was happy I was contributing from the outside. But was that enough?

\section{Stepping up}

One morning in May, I received a phone call from the Covid ward in-charge at my centre to ask if I would be comfortable with treating Covid patients. It was a moment of joy, I felt like I belonged. The need to serve was so strong that it made me resilient to all the resistance I faced from others. It helped me overcome all their fears. Meanwhile, the guidelines in physiotherapy for management of acute symptoms were formulated to put up to the council. Our off-the field work had made its way directly on to the field.

The next morning as I stood outside the Covid ICU, thoughts and emotions flooded my mind. I did not want my elderly mother to be anxious, so I had not informed her -- it had already been more than two months since I had met her. My husband and daughter were already working at a Covid ICU, and I got strength from them. I was used to their routine ritual of taking their shoes off outside, heading straight for a hot bath without touching anything in the house, clothes being soaked in hot water before washing, phones being sanitised, leaving wallets at the entrance, and every small precaution they took. I was asked if I required separate accommodation, which I refused. I knew we could handle the situation at home, we had each other to fall back on, and that's probably all that the three of us needed.

We moved towards the closed door of the isolation ward. This was the moment that said "You are entering a zone not permitted to all. Be careful, Stay safe". The corridors and wards 
which I had roamed for the past 20 years had become an environment which carried fear in the air.

The increasing cases had compelled the hospital's conversion of its wards into intensive care units and its open grounds into Covid care centres. Monitors and ventilators were placed at every bed and everyone had varying degrees of oxygen support, all critical. I felt lost, I could identify nurses and residents as they had stickers on their personal protective equipment (PPE) and I had one marking me as a physiotherapist which gave me my identity. I stood and wondered where to begin. I was asked to see a lady in the side room, the wife of a faculty member, comparatively stable. On speaking with her, I understood hers was the mildest case. I could see that the others were eagerly waiting for their turn to be approached.

\section{Initial challenges}

Talking with a PPE on, especially the N95 mask and face shield, makes it difficult to speak. Neither are you audible to your patients, nor can you hear them from a distance, and if you shout to be heard, your voice becomes hoarse. Having anticipated these problems, the big posters provided with clear images and instructions for breathing exercises were a great help. I spoke using sign language as the posters instructed, and when this was understood I sighed in relief. I was becoming more confident.

This ICU was different from the others, more challenging. The sound of the ventilators and monitors was loud, intimidating. I could see some patients struggle to breathe, even on respiratory support, constantly moving to find the most comfortable position. I doubted that the ventilators were doing their job. An elderly man of about 75 years caught my attention. His mask with a rebreathing bag had been put aside on the bed. I went to him and put it on his face. The morning breakfast of milk and bread lay on the trolley beside him, as though he had given up on himself. The lady on the bed diagonally opposite called me with a gesture of her hand. I did not know her name and I asked my resident to go to her. Her file mentioned "Mrs Son non-invasive (NIV) respiratory support". She wanted to remove her mask and drink water and her eyes looked at me for help. Unsure, I checked her file and spoke to the doctor. I had to be alert as the patients' oxygen saturation levels fell very fast. My eyes were constantly focused on the monitor and I was trying to check, finger probe well in place, making doubly sure that the monitor display was right. Her NIV mask was immediately put back and my heart throbbed while she took a sip of water. I asked her to lie prone. She refused."Mrs S, it is important. Please try. We will help you. We need to get your lung better," we coaxed her. Taking care of her lines and tubes we assisted her to lie on her side. When she indicated that she was comfortable, we helped her into the position needed.

My attention was drawn back to Mr J. He had been admitted after a stroke. He had removed his mask once again. I felt disturbed about his noncompliance with the mask. "Why can't he understand?" I asked myself. It was not possible for him to sit unassisted because of poor control over his body. I knew he had to be assisted to relearn to breathe, to sit and stand gradually. All this was not possible without a compassionate touch and a firm hold. The two of us held him tight as he tried to stand. He was standing up for the first time in ten days, with his eyes gleaming. We gave him a thumbs-up. Victory was achieved, or at least we were on the way. Every step mattered.

Contactless therapy was something impossible in here, I thought. No family member was present to call out to, or help make the patient sit up, or feed or assist in care. In Indian culture, the family forms an important support force to assist in patient care. The "F" for family from the ABCDEF bundle of ICU care was severely missed. Visiting the washroom was not possible for anyone, and my first challenge was to make the patients functionally independent and prevent de-saturation by improving their lung status.

The clock on the wall told me that the time spent inside the Covid zone was not adequate, as we reasoned the 3 Ps prioritise, position and pace - for patient management strategy. The major mode of communication was nonverbal, since our faces were hidden behind the PPE and human touch was masked through the gloves.

\section{Familiarity and confidence}

As days passed, I became more familiar to the patients. Being recognised through the PPE was an achievement in itself. Mr J began his breathing exercise as I entered the ward. His eyes following me. Mrs $\mathrm{S}$ was stabilising too. The fear of death had been overcome and a bond was formed. I was happy to see her being taken off the respiratory support as she was being transferred out of the ICU. She asked "Will you come to that ward to see me? I am still not strong." Mr J maintaining his saturation, now readily agreed to do exercises in and out of bed with support. The medicines and rehab were working hand in hand. I heard him speak for the first time with a speech that was slurred as he said "Thank you".

As they emerged stronger and more confident, I knew talking eased their anxiety. I questioned myself had I made a difference? and the answer was in their smiles as they left for home, their ability to recognise me through PPE, and a message from home 'Abhi thoda khasi hai. Lekin walk kar sakta hun. Aap ko milne kabhi aaun? [I have a slight cough now. But I can walk. When may I come and see you?]." Everyone is a hero. A lesson well learnt.

\section{Conflict of interest and funding: None declared.}

Acknowledgements: The author would like to acknowledge the contributions of Dr Padmaja Samant, Professor, Department of Obstetrics and Gynaecology, Seth GSMC and KEM Hospital and Dr Farah Jiandani for editing and feedback. 